\title{
Maternal levels of endocrine disruptors, polybrominated diphenyl ethers, in early pregnancy are not associated with lower birth weight in the Canadian birth cohort GESTE
}

Yasmine K. Serme-Gbedo ${ }^{1}$, Nadia Abdelouahab ${ }^{1}$, Jean-Charles Pasquier ${ }^{2}$, Alan A. Cohen ${ }^{3}$ and Larissa Takser ${ }^{1 *}$

\begin{abstract}
Background: Polybrominated diphenyl ethers are known endocrine disrupting environmental contaminants used as flame retardants. Their levels have increased in humans over the last ten years, raising concerns about their consequences on human health. Some animal studies suggest that PBDEs can affect fetal growth; however, the results of human studies are contradictory. This study evaluates the association between the most common PBDEs in maternal blood measured in early pregnancy and birth weight.
\end{abstract}

Methods: BDE-47, BDE-99, BDE-100 and BDE-153 levels were measured in 349 women during their first prenatal care visit at the University Hospital Center of Sherbrooke (Quebec, Canada). Birth weight and relevant medical information were collected from medical records. In contrast with previous studies, we examined the full range of clinical risk factors known to affect fetal growth as potential confounders, as well as other environmental pollutants that are likely to interact with fetal growth (polychlorinated biphenyls (PCBs), mercury, lead, cadmium and manganese).

Results: There was no statistically significant relationship between PBDE levels in early pregnancy and birth weight in both unadjusted and multivariate regression models.

Conclusions: Our results suggest that PBDEs in early pregnancy have little or no direct impact on birth weight, at least at the levels of exposure in our population.

Keywords: Polybrominated diphenyl ethers, Pregnancy, Birth weight, Polychlorinated biphenyls, Mercury, Lead, Cadmium, Manganese

\section{Background}

Polybrominated diphenyls ethers (PBDEs), are ubiquitous environmental contaminants widely used as flameretardants in many consumer products (polyurethane foams used in furniture, mattresses, carpet pads and automobile seats and styrene plastics used for electrical appliances and flame-retardant textiles) [1]. PBDEs have been the focus of research over the past decade due to their ubiquitous presence in the environment $[2,3]$ and

\footnotetext{
*Correspondence: Larissa.Takser@usherbrooke.ca

'Department of Pediatrics, Faculty of Medicine, University of Sherbrooke,

3001 12e Avenue Nord, Sherbrooke, Quebec J1H 5N4, Canada

Full list of author information is available at the end of the article
}

the human body (adipose tissue, blood, and breast milk) [3] in addition to their endocrine disrupting properties [4]. Furthermore, they are lipophilic compounds which easily cross the placental barrier.

Several reports, including ours $[5,6]$, indicate that PBDEs are thyroid disruptors in animals and humans, and a few studies suggest that PBDEs may potentially disrupt the insulin-like growth factor (IGF) system, which is an anabolic stimulus of fetal growth [7]. Indeed, uterine expression of insulin-like growth factor 1 (IGF-1) was upregulated in adult rat offspring exposed prenatally to $1 \mathrm{mg} /(\mathrm{kg}$ day) of BDE-99 [8]. Another study found that perinatal exposure to $0.002-0.2 \mathrm{mg} \mathrm{BDE}-47 / \mathrm{kg}$ increased 
body weight in all Wistar rat offspring, accompanied by increased plasma IGF-1 and glucose uptake in males (but not in females) [9]. To our knowledge, only two studies have examined the relationship between the IGF system and PBDEs in humans. The first study found a positive association between breast milk BDE-196 and IGF-1 in the cord blood from 149 women in the general Taiwanese population but they also found a negative association for BDE-99 and 86 [10]. The second study suggested a positive correlation between umbilical cord serum PBDE levels and placental gene expression of insulin-like growth factor binding protein 3 (IGFBP-3) among Chinese children living in one of the world's largest electronic waste sites [11].

We hypothesized that, through their interaction with the IGF system, PBDEs could influence BW. Considering the role of IGF-1 and IGFBP-3 in the regulation of fetal growth [12], a positive association between prenatal exposure to PBDEs and these hormones may lead to a positive association between PBDEs and BW. However, among the nine epidemiological studies assessing the relation between PBDEs and BW (see Table 1), four studies reported a significant, negative association [13-16], two studies reported a non significant, negative association $[17,18]$, two others reported no statistically significant association $[19,20]$, and one study suggested a negative association for male infants and a positive association for female [21]. However, these epidemiological findings (i) were based on designs differing from each other and from our study, (ii) did not consider other ubiquitous environmental pollutants which could also affect fetal growth and (iii) did not take into account the relationship between $\mathrm{BW}$ and gestational age.

The present study examines the association between PBDEs in early pregnancy and BW in our prospective birth cohort, GESTE (GEStation Thyroid and Environment), which has been specifically designed to study health outcomes related to PBDE exposure in pregnant women and their children. We focus on the most prevalent PBDE congeners in maternal and umbilical-cord blood, which are BDE-47, BDE-99, BDE-100, and BDE-153 [14, 22-24]. Because PCBs are suspected to be associated with BW (particularly CB-153, which was consistently shown to be negatively associated with $\mathrm{BW}$ [21]), we analyzed the most prevalent PCBs in our samples as potential confounding factors, as well as metals (mercury, lead, cadmium, and manganese), which are also ubiquitous in the environment and have been reported to have an impact on fetal growth [25-30].

\section{Methods}

\section{Population recruitment}

In the GESTE cohort, we recruited pregnant women at their first prenatal visit (mean gestational age $=12$ weeks,
Table 1 Characteristics of 349 mothers-newborn in GESTE study, Quebec, Canada, 2007-2008

\begin{tabular}{|c|c|}
\hline Characteristics (range and unit) & $\begin{array}{l}\text { Mean (SD) } \\
\text { No }(\%)\end{array}$ \\
\hline Total population & $349(100)$ \\
\hline \multicolumn{2}{|l|}{ Newborn characteristics } \\
\hline Male & $179(51.3)$ \\
\hline Birth weight (1,555 to $4,705 \mathrm{~g})$ & $3,366.6(504.1)$ \\
\hline Low birth weight $(\mathrm{BW}<2500 \mathrm{~g})$ & $16(4.6)$ \\
\hline $\begin{array}{l}\text { Gestational age at recruitment ( } 3.3 \text { to } 28.6 \text { weeks } \\
\text { of amenorrhea) }\end{array}$ & $11.01(2.9)$ \\
\hline $\begin{array}{l}\text { Gestational age at birth (30.3 to } 42.3 \text { weeks of } \\
\text { amenorrhea) }\end{array}$ & $39.3(1.6)$ \\
\hline $\begin{array}{l}\text { Prematurity (Gestational age at birth }<37 \text { weeks } \\
\text { of amenorrhea) }\end{array}$ & $23(6.6)$ \\
\hline \multicolumn{2}{|l|}{ Maternal characteristics } \\
\hline Age at delivery (18 to 40 years) & $28.8(4.4)$ \\
\hline Married or common-law relationship & $323(93)$ \\
\hline BMl at recruitment (16.4 to $48.9 \mathrm{~kg} / \mathrm{m}^{2}$ ) & $25.9(5.9)$ \\
\hline Smoked during pregnancy & $65(19)$ \\
\hline Alcohol consumption during pregnancy & $19(5.4)$ \\
\hline Recreational drug consumption during pregnancy & $5(1.4)$ \\
\hline Infection during pregnancy & $32(9)$ \\
\hline $\begin{array}{l}\text { Previous low birth weight }(<2500 \mathrm{~g}) \text { infant in } \\
\text { multipara }(n=236)\end{array}$ & $28(12)$ \\
\hline Previous preterm infant in multipara $(n=236)$ & $16(7)$ \\
\hline \multicolumn{2}{|l|}{ Inter pregnancy interval ${ }^{a}$} \\
\hline Low (<18 months) & $57(24.3)$ \\
\hline$\geq 18$ and $\leq 60$ months & $147(62.5)$ \\
\hline Large (>60 months) & $31(13.2)$ \\
\hline
\end{tabular}

Abbreviation: $S D$ standard deviation

${ }^{\mathrm{a}}$ Time interval between pregnancy before and GESTE pregnancy

$\mathrm{SD}=2.96$ weeks). As previously described [6], 400 eligible women who agreed to participate at their first prenatal care visit at the Research Center of the CHUS (Centre Hospitalier Universitaire de Sherbrooke) in Quebec, Canada, between September 2007 and December 2008, were included. Virtually all pregnant women living in the region served by the CHUS are seen in early pregnancy for routine clinical tests including blood and urine sampling. Eligibility criteria were maternal age ( $\geq 18$ years), gestational age $<20$ weeks, and no known thyroid disease. Given our intention to follow children from recruited pregnancies, we excluded women who planned to move out of the region in the following three years. Gestational age was confirmed by ultrasonography. For this paper, four pregnancies for which gestational age was found to be $>20$ weeks based on ultrasonography were kept in our analyses. We estimate the rate of refusal to participate to be less than $5 \%$ for eligible women approached by members of the research team. Maternal blood was collected at recruitment in 
10-mL Vacutainer Hemogard tubes with ethylenediaminetetraacetic acid (Becton-Dickinson, San Jose, California). The plasma was frozen at $-20{ }^{\circ} \mathrm{C}$ in decontaminated Supelco glass storage tubes (Supelco, Inc., Bellefonte, Pennsylvania) for PBDEs, PCBs and thyroid hormone dosing. Blood was also obtained in $10-\mathrm{mL}$ metal-free blood collection tubes with $0.05 \mathrm{~mL}$ of $15 \%$ ethylenediaminetetraacetic acid $\mathrm{K} 3$ and stored at $4{ }^{\circ} \mathrm{C}$ for manganese, lead, mercury and cadmium analysis.

The study protocol was approved by the Human Research Ethics Committee of the CHUS, and an informed consent form was signed by each participant.

\section{Data collection}

\section{Outcome measurement}

Information on BW was obtained from medical records completed at delivery by the obstetrical team who weighed newborns with a Scale-tronix pediatrics scale 4802 .

\section{Laboratory analysis}

PBDE and PCB levels Plasma levels of PBDEs (BDE-47, BDE-99, BDE-100, and BDE-153) and PCBs (CB-138, CB153 , and $\mathrm{CB}-180$ ) were analyzed in our laboratory based on the method described by Covaci and Voorspoels [31].

Quality control was conducted through regular analyses of water blanks added at every 10th sample, solvent blanks, and random duplicate samples. All blanks were subtracted from sample values on a batch basis. Interbatch coefficients of variation were $\leq 10 \%$ and $\leq 8 \%$ for PBDEs and PCBs, respectively. Limits of detection (LOD), defined as 3 times the noise level, were established at $0.1 \mathrm{pg} / \mu \mathrm{L}$ for PBDEs and at $0.02 \mathrm{pg} / \mu \mathrm{L}$ for PCBs. Routine checks of accuracy and precision were also performed using reference materials (1589a) from the National Institute of Standards and Technology (Gaithersburg, MD, USA). Recoveries ranged between 75 and $125 \%$. Here, we used the sums of PBDE and PCB levels across classes, as well as the levels of individual PBDEs and PCBs.

Metal levels Whole blood manganese, lead, cadmium and mercury level determinations were performed by the Toxicology Center of Quebec at the Quebec Institute for Public Health (CTQ-INSPQ). Cold vapor atomic absorption spectrophotometry was used for total blood mercury and mass spectrometry plasma torch (ICP-MS) for lead, cadmium and manganese.

Limits of detection were $2.07 \mu \mathrm{g} / \mathrm{L}$ for lead, $0.1 \mu \mathrm{g} / \mathrm{L}$ for mercury, $0.05 \mu \mathrm{g} / \mathrm{L}$ for cadmium, and $4.4 \mu \mathrm{g} / \mathrm{L}$ for manganese.

\section{Other relevant information}

Following inclusion, women answered a questionnaire administered by a research nurse who also measured women's height and weight. The questionnaire was used to obtain women's birth dates, education, marital status, income, obstetrical history, smoking habits, consumption of alcohol and recreational drugs. Another questionnaire was administered after delivery by phone to complete data for the period between recruitment and delivery. Pregnancy follow-up data (infection during pregnancy, BW and baby sex) were also extracted from medical records and gestational ages at recruitment and birth were calculated from the ultrasonography (see Additional file 1: Table S1 for details).

\section{Statistical analysis}

All analyses were performed with SAS/STAT software (SAS version 9.3) [32]. PBDE levels were analyzed in 386 of 400 participants due to the loss of 11 samples as a result of analytical problems and the exclusion of twin pregnancies $(n=3)$ post-hoc, for a total of 14 samples. Additional losses to follow-up included 27 women with miscarriages, 5 with voluntary abortions and 5 who delivered in another hospital. Our analyses were therefore run on 349 newborn-mother pairs.

Analyses were conducted as follows: 1) Descriptive statistics on exposure data, BW, and potential confounding factors or modifiers were calculated. 2) Bi-variate Spearman correlation analysis was performed to determine potential colinearities between contaminants, BW and blood sampling time (gestational age at recruitment). 3) Simple and multivariate linear regressions were carried out to study the association between BW and PBDEs.

A major challenge for a study of this nature is the lack of empirical or biological basis for choosing among an excessively large number of potential model specifications. In particular, covariates and confounders are problematic, given that many potentially important variables have not been measured in previous studies, and that the evidence on causal pathways necessary for constructing a directed acyclic graph is largely absent. Additionally, BW and gestational age are closely, non-linearly associated, and we are not able to confirm if PBDEs could act on either gestational duration as suggested in one preceding study [33] or on growth rates, creating a collider bias in estimating the association between PBDE and BW if adjusted on gestational age [34]. In addition, given that lipophilic pollutants, such as PCBs (and PBDEs) are bound to blood lipids $[35,36]$, the metabolism of which is rapidly changing in early pregnancy [37], we need to consider different types of multivariate modeling to take into account possible causal pathways.

To find the most relevant multiple regression models, we first tested the relationship between BW and (i) other pollutants (PCBs, cadmium, lead, mercury, manganese), (ii) potential confounders or modifiers, which have been extensively reviewed and shown to be moderately or 
strongly associated with low BW by the Institute of Health Economics (IHE) [38]. These potential confounders were: gestational age at birth, mother's age at delivery, marital status (single or not), Body Mass Index (BMI) at recruitment, infection, smoking status, alcohol and recreational drug consumption during pregnancy, and inter-pregnancy interval. We have also tested infant sex and gestational age at recruitment as potential covariates [39]. Since a previous study found a different association between PBDEs and IGF-1 according to sex [9], we also tested the statistical interaction between sex and PBDE levels. Since this interaction was not significant, these data are not shown.

Our initial models were simple linear regression between PBDEs and BW. Covariates were included in multiple linear regression models if they were associated in bivariate analyses with one PBDE congener or the sum of $\mathrm{PBDE}$ and $\mathrm{BW}$ at $P<0.25$. The following variables were included in final multivariate models: mother's age, marital status, BMI, infections, smoking, PCBs, and lead levels. We used the sum of PCBs (CB-138, 153, 180) in our analyses as they were inter-correlated (Table 3 ).

\section{Dependent variable}

Gestational age was the most correlated with BW ( $r=$ $0.53, p<0.001)$. To avoid collider bias [34], we created a dependent variable "BW corrected for gestational age", which was used in all subsequent statistical models. The correction of BW was done using residues from nonparametric regression "SAS PROC LOESS" with 0.75 as the smoothing parameter (see Additional file 1: Figure S1), as follows:

proc sort data $=$ donnees; by id; run;

ods output OutputStatistics $=$ b FitSummary $=$ summary ;

proc loess data $=$ donnees;

model birthweight $=$ gest_age $/$ smooth $=\mathbf{0 . 7 5} \mathrm{clm}$ direct degree $=\mathbf{2} ;$ run;

proc means data=donnees; var birthweight;

output out $=\mathrm{c}$ mean $=$ ym;run;

data d; merge b c;

if $\_\mathrm{n}_{-}=\mathbf{1}$ then $\mathrm{ymm}=\mathrm{ym}$; retain ymm;run;

data donnees; merge donnees $\mathrm{d}$;

bw=residual+ymm;run;

We choose this procedure because the inter-quartile interval of residues in this model was smaller compared with linear, spline or curviline regression. The obtained residuals were normally distributed ( $p$-value for Kolmogorov-Smirnov > 0.25).

\section{Independent variable related to PBDE exposure}

Among the 349 samples, $5 \%, 23 \%$ and $21 \%$ (Table 2) were below the limit of detection (LOD), which were for BDE-99 $(\mathrm{LOD}=0.001 \mathrm{ng} / \mathrm{mL}), B D E-100 \quad(\mathrm{LOD}=$ $0.001 \mathrm{ng} / \mathrm{mL})$ and $\mathrm{BDE}-153(\mathrm{LOD}=0.0006 \mathrm{ng} / \mathrm{mL})$, respectively. We ran linear regression analysis using PBDEs congener individually by replacing below-LOD values by LOD/2. To create the summed values ( $\Sigma$ PBDEs and $\Sigma$ PCBs), values below the limit of detection we used zero for undetectable congeners.

Each PBDE congener was introduced in regression models separately to avoid potential colinearity. In addition, we used the sum of PBDEs as commonly used in the literature in order to compare our results with previous studies. We have verified that for all models, residuals were normally distributed ( $p$-value for KolmogorovSmirnov test $>5 \%$ ).

For each congener, we ran both: (i) volume-based models where total plasma lipid levels were introduced as an independent variable, and (ii) lipid-based models where PBDEs were expressed in ng/g lipids.

Underlying distributions of PBDE congeners appeared to be $\log$-normal, so $\log _{10}$ transformation improved normality. Thus, we ran regression models using (i) PBDEs non transformed concentrations and (ii) $\log _{10}$-transformed PBDEs. In the results section, we only present the results with PBDEs $\log _{10}$-transformed. Results with non transformed PBDEs are presented in Additional file 1: Table S3.

\section{Results}

Socio-demographic information, lifestyle habits, BMI at recruitment, obstetric history and pregnancy outcomes are presented in Table 1 . The majority of women were married or in a common-law relationship (93\%) and $68 \%$ were multiparous. Among multiparous women $12 \%$ and $7 \%$ had a history of low birth weight or premature delivery, respectively. The time interval between their last delivery and the current pregnancy ranged between 18 and 60 months for $63 \%$, less than 18 months for $24 \%$ and more than 60 months for $13 \%$ of multiparous women. Regarding mothers' lifestyle factors, $19 \%$ reported being active cigarette smokers (the number of cigarettes per day ranged from one to 20 in the first trimester and from one to 15 in both the second and third trimesters), $5 \%$ to having consumed alcohol at least once and $1 \%$ to having used recreational drugs during pregnancy. At recruitment, the women ranged from 18 to 40 years old with an average age of 28 years. Their BMI was between 16 to $49 \mathrm{Kg} / \mathrm{m}^{2}$ at inclusion (average of $26 \mathrm{Kg} / \mathrm{m}^{2}$ ). Fifty-one percent of babies were male, sixteen babies (4.6\%) weighed less than $2500 \mathrm{~g}$ at 
Table 2 Levels of PBDEs, PCBs, selenium, mercury, lead, cadmium and manganese in early pregnancy $(N=349)$

\begin{tabular}{|c|c|c|c|c|c|}
\hline & $\%$ of detected values & $25^{\text {th }}$ percentile & $50^{\text {th }}$ percentile & $75^{\text {th }}$ percentile & Maximum \\
\hline \multicolumn{6}{|l|}{ PBDE congeners (ng/mL) } \\
\hline PBDE-47 & 100 & 0.07 & 0.12 & 0.25 & 2.74 \\
\hline PBDE-99 & 95 & $5.10^{-3}$ & 0.01 & 0.03 & 0.48 \\
\hline PBDE-100 & 77 & $4.10^{-3}$ & $7.10^{-3}$ & 0.01 & 0.36 \\
\hline PBDE-153 & 79 & $8.10^{-3}$ & 0.02 & 0.05 & 0.39 \\
\hline$\sum$ PBDES & & 0.10 & 0.19 & 0.34 & 3.63 \\
\hline \multicolumn{6}{|c|}{ PBDE congeners (ng/g of lipids) } \\
\hline PBDE-47 & & 10.78 & 21.23 & 40.82 & 548.00 \\
\hline PBDE-99 & & 0.76 & 1.93 & 5.44 & 96.00 \\
\hline PBDE-100 & & 0.66 & 1.32 & 2.44 & 81.63 \\
\hline PBDE-153 & & 1.08 & 2.44 & 8.97 & 85.33 \\
\hline$\Sigma$ PBDES & & 17.08 & 32.99 & 59.63 & 726.00 \\
\hline \multicolumn{6}{|l|}{ PCBs (ng/g of lipid) ${ }^{a}$} \\
\hline PCB-138 & 93 & 2.29 & 4.25 & 10.41 & 178.04 \\
\hline PCB-153 & 99 & 4.55 & 8.02 & 19.80 & 410.43 \\
\hline PCB-180 & 100 & 2.02 & 4.11 & 9.02 & 90.91 \\
\hline$\Sigma \mathrm{PCBS}$ & & 10.91 & 18.87 & 42.80 & 455.78 \\
\hline \multicolumn{6}{|l|}{ Metals ${ }^{b}$} \\
\hline Manganese (ng/mL) & 100 & 7.70 & 9.35 & 11.55 & 32.45 \\
\hline Mercury (ng/mL) & 85 & 0.38 & 0.62 & 1.01 & 6.83 \\
\hline Lead (ng/mL) & 100 & 6.21 & 8.28 & 10.35 & 64.17 \\
\hline Cadmium (ng/mL) & 100 & 0.11 & 0.22 & 0.36 & 6.04 \\
\hline
\end{tabular}

Abbreviations: $P B D E(s)$ polybrominated diphenyl ether(s), $\Sigma P B D E$ total PBDEs, $P C B(s)$ polychlorinated biphenyl(s), $5 P C B s$ total PCBs

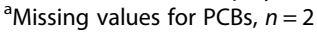

${ }^{\mathrm{b}}$ Missing value for at least one metal $(n=57)$

birth and 23 (6.6 \%) were born prematurely (gestational age $<37$ weeks).

PBDE, PCB and metal levels are shown in Table 2 and their inter-correlations are shown in Table 3. CB-138, 153 and 180 were detected respectively in $93 \%, 99 \%$ and $100 \%$ of the samples. PBDE levels were inter-correlated among congeners, but not all correlations were strong, and were generally weaker than among PCB congeners. Lead, cadmium and manganese were detected in all maternal samples. Manganese levels ranged between 4.4 and $32.45 \mu \mathrm{g} / \mathrm{L}$. Mercury was detected in $85 \%$ of cases in concentrations ranging from 0.1 to $6.8 \mu \mathrm{g} / \mathrm{L}$. Among metals, inter-correlations ranged between -0.07 and 0.31 .

The results of simple linear regression between BW and potential confounders are detailed in Additional file 1: Table S2. Gestational age at birth, sex, infection, smoking during pregnancy and maternal pre-pregnancy BMI, maternal blood levels of cadmium were significantly associated with $\mathrm{BW}$ at $p<0.05$. In these relationships, gestational age at birth explained $28 \%$ and sex $2 \%$ of BW variance. The variance explained by other confounders ranged from $0.4 \%$ for inter-pregnancy interval to $2 \%$ for maternal BMI at recruitment and maternal infection during pregnancy. Early pregnancy levels of cadmium explained $1 \%$ and PCBs explained $0.8 \%$ of $\mathrm{BW}$ variance, respectively.

Table 4 shows the results of linear regression models for PBDEs (each congener and the sum) in early pregnancy (expressed in $\mathrm{ng} / \mathrm{g}$ of lipid and $\log _{10}$-transformed) in relation to BW corrected for gestational age. PBDEs were not significantly associated with BW corrected for gestational age in both adjusted and unadjusted linear regression. Furthermore, all these associations remained non-significant in linear regressions adjusted for confounding factors. Interactions between sex and PBDEs were never statistically significant (data not shown).

In sensitivity analyses we excluded neonates born before the $37^{\text {th }}$ week of gestation but the model estimates did not change substantially. We also conducted the same analyzes excluding subjects with BDE-99, BDE-100, or BDE153 below LOD, but did not observe any change in the results.

\section{Discussion}

We found no statistically significant association between BW and levels of BDE-47, BDE-99, BDE-100, BDE-153 
Table 3 Spearman correlation coefficients for PBDEs, PCBs, mercury, lead, cadmium, manganese levels, birth weight and gestational age at recruitment $(N=349)$

BW GAR Cadmium Manganese Mercury Lead Sum of BDE-47 BDE-99 BDE-100 BDE-153 Sum of CB-138 CB-153
PBDES $\quad$ PCBS

\begin{tabular}{|c|c|c|c|c|c|c|c|c|c|c|c|c|c|c|}
\hline BW & - & & & & & & & & & & & & & \\
\hline GAR & -0.03 & - & & & & & & & & & & & & \\
\hline Cadmium & $-0.12^{*}$ & 0.02 & - & & & & & & & & & & & \\
\hline Manganese & 0.05 & -0.06 & -0.07 & - & & & & & & & & & & \\
\hline $\mathrm{HgT}$ & -0.01 & -0.02 & 0.07 & $0.31^{* * *}$ & - & & & & & & & & & \\
\hline Lead & -0.10 & -0.01 & $0.24 * * *$ & $0.25^{* * *}$ & $0.17^{* *}$ & - & & & & & & & & \\
\hline Sum of PBDEs & 0.03 & 0.05 & -0.03 & 0.00 & 0.04 & -0.02 & - & & & & & & & \\
\hline BDE-47 & 0.05 & 0.08 & -0.03 & -0.01 & 0.04 & -0.04 & $0.95^{* * *}$ & - & & & & & & \\
\hline BDE-99 & 0.06 & -0.004 & -0.02 & 0.00 & 0.01 & -0.03 & $0.73^{* * *}$ & $0.58^{* * *}$ & - & & & & & \\
\hline BDE-100 & 0.02 & 0.06 & -0.04 & 0.03 & 0.00 & 0.06 & $0.28^{* * *}$ & 0.11 & $0.19^{* *}$ & - & & & & \\
\hline BDE-153 & -0.09 & -0.09 & 0.01 & 0.01 & 0.00 & 0.10 & $0.53^{* * *}$ & $0.32^{* * *}$ & $0.54^{* * *}$ & $0.14^{*}$ & - & & & \\
\hline Sum of PCBs & 0.08 & $0.12^{*}$ & -0.08 & $0.12^{*}$ & 0.06 & 0.08 & $0.26^{* * *}$ & $0.26^{* * *}$ & $0.22^{* * *}$ & 0.09 & $0.12^{*}$ & - & & \\
\hline CB-138 & $0.10^{*}$ & $0.10^{*}$ & -0.05 & 0.08 & 0.03 & 0.04 & $0.12^{*}$ & $0.13^{*}$ & 0.08 & 0.09 & 0.06 & $0.76^{* * *}$ & - & \\
\hline CB-153 & 0.05 & 0.09 & -0.06 & $0.14^{*}$ & 0.06 & 0.05 & $0.31^{* * *}$ & $0.32^{* * *}$ & $0.25^{* * *}$ & $0.06^{* * *}$ & 0.09 & $0.84^{* * *}$ & 0.39 & - \\
\hline CB-180 & 0.046 & 0.09 & -0.06 & 0.03 & 0.04 & $0.12^{*}$ & $0.13^{*}$ & $0.12^{*}$ & $0.17^{* *}$ & 0.06 & $0.17^{* *}$ & $0.75^{* * *}$ & $0.49^{* * *}$ & $0.46^{* * *}$ \\
\hline
\end{tabular}

All contaminants were expressed in $\mathrm{ng} / \mathrm{mL}$ and below-LOD values were excluded. BW is expressed in $\mathrm{g}$ GAR Gestational age at recruitment

${ }^{*}<0.05 ;{ }^{* *}<0.01 ; * * * 0.0001$

and their sum. The absolute values of the slopes in regressions vary between 0.8 and $70.4 \mathrm{~g}$ of $\mathrm{BW}$, suggesting a tiny clinical effect for a 10 fold increase in the concentration of PBDEs. These findings remained unchanged in both volume-based and lipid-based models.

Our study has the following methodological strengths (i) a large sample size, (ii) extensive measurement of known clinical and lifestyle risk factors for intrauterine growth restriction and measured levels of other environmental exposures (cadmium, manganese, lead, PBCs, and mercury), which have been reported to be negatively correlated with BW in the general population [25-30], (iii) replication of results across a wide range of modeling approaches, given the weak a priori knowledge available to support model construction; and (iv) the use of $\mathrm{BW}$ independently of its association with gestational age.

One of potential limitations of our study is that two PBDE congeners (BDE-100 and BDE-153) were undetectable in $23 \%$ and $21 \%$ of the samples, respectively. In our statistical analyses we considered them as LOD/2, which might induce an under or overestimation of regression slopes. However, we conducted sensitivity analyses, in which we excluded undetectable data and we obtained similar results.

Our population is representative of Canadian pregnant women for blood metal levels, maternal age and birth weight [40]. However, a greater proportion of the pregnant women in our study were smokers (19\%) compared to Canadian pregnant women (15\%) [41]. Alcohol consumption reported by the pregnant women in our study group (5\%) is lower than in Canada (15\%) and significantly lower compared to the rest of the Quebec province (26\%) [42]. High education levels in our study group was higher compared to pregnant women in Canada [42], which could be partly related to our inclusion criteria as well to the specificity of our recruitment area (Sherbrooke has two Universities and two regional Colleges). Median family income (CAD\$60,000) was similar compared to women in Quebec in 2009 (CAD\$64,000) [42]. An additional difference consists of the fact that the absolute majority of pregnant women were Caucasian (of French or Irish origin), which reflects an historical particularity of our area. Globally, our study group was more educated and more genetically homogenous, but similar to Canadians in terms of environmental exposures and birth weight. We believe that the high homogeneity of our study group represents an advantage for testing the effects of environmental exposures, because this situation is closer to a quasi-experimental design.

In Table 5, we summarized all available epidemiological data (9 publications) on PBDEs and BW. Four of them reported a negative association between PBDE levels in mothers and BW [13-16]. Harley et al. [13] found a significant negative correlation between PBDE levels in the second trimester and BW among 289 low income pregnant women who were also highly exposed to pesticides in California. In another study in Ontario, Canada [14], only BDE-99 in cord blood was negatively correlated with 
Table 4 Association between birth weight corrected for gestational age and maternal plasma levels of PBDEs (log 10$)$ in early pregnancy

\begin{tabular}{|c|c|c|c|c|c|c|}
\hline \multirow[t]{3}{*}{$\log _{10}$ PBDEs } & \multirow{2}{*}{\multicolumn{2}{|c|}{ Simple linear regressions ${ }^{a}$}} & \multicolumn{4}{|c|}{ Multivariate linear regression ${ }^{b}$} \\
\hline & & & \multicolumn{2}{|c|}{ Model A } & \multicolumn{2}{|c|}{ Model B } \\
\hline & $\beta$ & $95 \% \mathrm{Cl}$ & $\beta$ & $95 \% \mathrm{Cl}$ & $\beta$ & $95 \% \mathrm{Cl}$ \\
\hline \multicolumn{7}{|c|}{$\log _{10}$ PBDEs (ng/g of lipid) } \\
\hline BDE-47 & 0.8 & $-93.1 ; 94.7$ & -25.1 & $-120.4 ; 70.3$ & -14.4 & $-129.9 ; 101.2$ \\
\hline BDE-99 & 33.7 & $-34.8 ; 102.2$ & 20.6 & $-49.1 ; 90.4$ & -1.6 & $-90.9 ; 87.7$ \\
\hline BDE-100 & 25.4 & $-32.5 ; 83.3$ & 23.9 & $-33.6 ; 81.5$ & 4.7 & $-67.2 ; 76.5$ \\
\hline BDE-153 & -49.6 & $-100.9 ; 1.7$ & -40.7 & $-91.9 ; 10.6$ & -55.9 & $-118.9 ; 6.9$ \\
\hline$\Sigma$ PBDEs & -25.4 & $-128.7 ; 77.9$ & -46.1 & $-151.3 ; 59.1$ & -44.7 & $-173.6 ; 84.1$ \\
\hline \multicolumn{7}{|c|}{$\log _{10}$ PBDEs $(\mathrm{ng} / \mathrm{ml})^{\mathrm{c}}$} \\
\hline $\mathrm{BDE}-47$ & 13.6 & $-82.7 ; 109.9$ & -16.1 & $-113.5 ; 81.3$ & 3.0 & $-115.9 ; 121.9$ \\
\hline BDE-99 & 46.7 & $-27.1 ; 120.5$ & 30.1 & $-45.2 ; 105.4$ & 10.2 & $-86.7 ; 107.1$ \\
\hline BDE-100 & 30.7 & $-27.8 ; 89.2$ & 27.9 & $-30.1 ; 85.9$ & 11.6 & $-61.0 ; 84.2$ \\
\hline BDE-153 & -49.7 & $-103.1 ; 3.7$ & -39.6 & $-103.0 ; 23.8$ & -55.0 & $-120.6 ; 10.6$ \\
\hline$\Sigma$ PBDEs & -12.3 & $-123.2 ; 98.5$ & -39.2 & $-151.7 ; 73.3$ & -27.0 & $-166.1 ; 112.0$ \\
\hline \multicolumn{7}{|c|}{$\log _{10}$ PBDEs (ng/ml) adjusted for total plasma lipids. } \\
\hline BDE-47 & 14.5 & $-81.8 ; 110.8$ & -16.2 & $-113.6 ; 81.2$ & 6.5 & $-112.3 ; 125.4$ \\
\hline BDE-99 & 70.4 & $-8.6 ; 149.4$ & 48.4 & $-32.3 ; 129.2$ & 42.1 & $-63.7 ; 147.9$ \\
\hline BDE-100 & 31.1 & $-27.4 ; 89.6$ & 27.9 & $-30.1 ; 85.8$ & 12.8 & $-59.7 ; 85.4$ \\
\hline BDE-153 & -45.4 & $-100.4 ; 9.6$ & -37.5 & $-92.2 ; 17.2$ & -47.1 & $-115.3 ; 21.1$ \\
\hline$\sum$ PBDEs & -2.6 & $-114.9 ; 109.7$ & -32.8 & $-146.5 ; 80.9$ & -9.3 & $-151.3 ; 132.6$ \\
\hline
\end{tabular}

Abbreviations: $\mathrm{Cl}$ confidence interval, $\mathrm{PBDE}(\mathrm{s})$ Polybrominated diphenyl ether(s), $\Sigma$ PBDE sum of BDE-47, 99,100 and 153

${ }^{\mathrm{a}}$ Non-adjusted for potential confounders

${ }^{\mathrm{b}}$ Adjusted for potential confounders

Model A: Adjusted on mother's age at delivery, marital status, BMI at recruitment, infection, smoking status during pregnancy, $\Sigma$ PCBs (CB-138, CB-153 and CB-180 expressed in $\mathrm{ng} / \mathrm{g}$ of lipid), mothers total blood levels of lead $(\mathrm{ng} / \mathrm{ml}$ )

Model B: Model A + previous pregnancies history (preterm infant and low birth weight infant) in multipara only $(N=234)$

'Total lipids were not taken into account in these models

BW. In a Swedish cross-sectional study of 254 motherbabies, PBDE levels in breast milk were associated with a decrease in BW specifically in male infants [16]. In Spain, Lopez-Espinosa et al. reported a negative significant association between BDE-99 and BW [15]. In other five studies, there was no association $[19,20]$, statistically not significant association [18], or a positive association in female only [21], or the number of subjects was too small to conclude $(n=20,[17])$.

The discrepancy among the results may be explained by the different designs of the studies, exposures levels, statistical analyses, adjustments methods, but also by the presence of underlying predisposing or susceptibility risk factors in a given population. An important aspect is that BW is a proxy for in utero growth, a multi-factorial phenomenon. Indeed, BW is influenced by multiple factors. These factors do not all have the same degree of influence and can interact synergistically or not, giving a multitude of possibilities [43]. This implies that the link between PBDEs and BW in two homogeneous (socially and/or genetically) populations with two different combinations of BW-related factors may not be the same. This theory was well explained by Rothman in 2005 [44]. He suggests that in multifactorial conditions, several causal components act in concert. A condition can be caused by different sets of combinations in different individuals or populations. Thus, it is possible that in our population, PBDEs have little or no role in determining BW, given the roles of genetic background, social environment, and complex interactions among these factors. Thus, our negative finding cannot exclude that PBDEs can affect populations with different social and/or genetic backgrounds.

For example, PBDE levels in the Californian study mentioned above were similar to those in our population [13] (Table 5). This study reported a negative association between PBDE levels in mid-pregnancy and BW in pregnant women from prenatal care clinics serving low-income residents who qualified for low-income health insurance (Medicaid). The majority (95\%) are Hispanic, while in our study, pregnant women were predominantly Caucasian Canadians $(96.5 \%)$ and had substantially higher socio- 


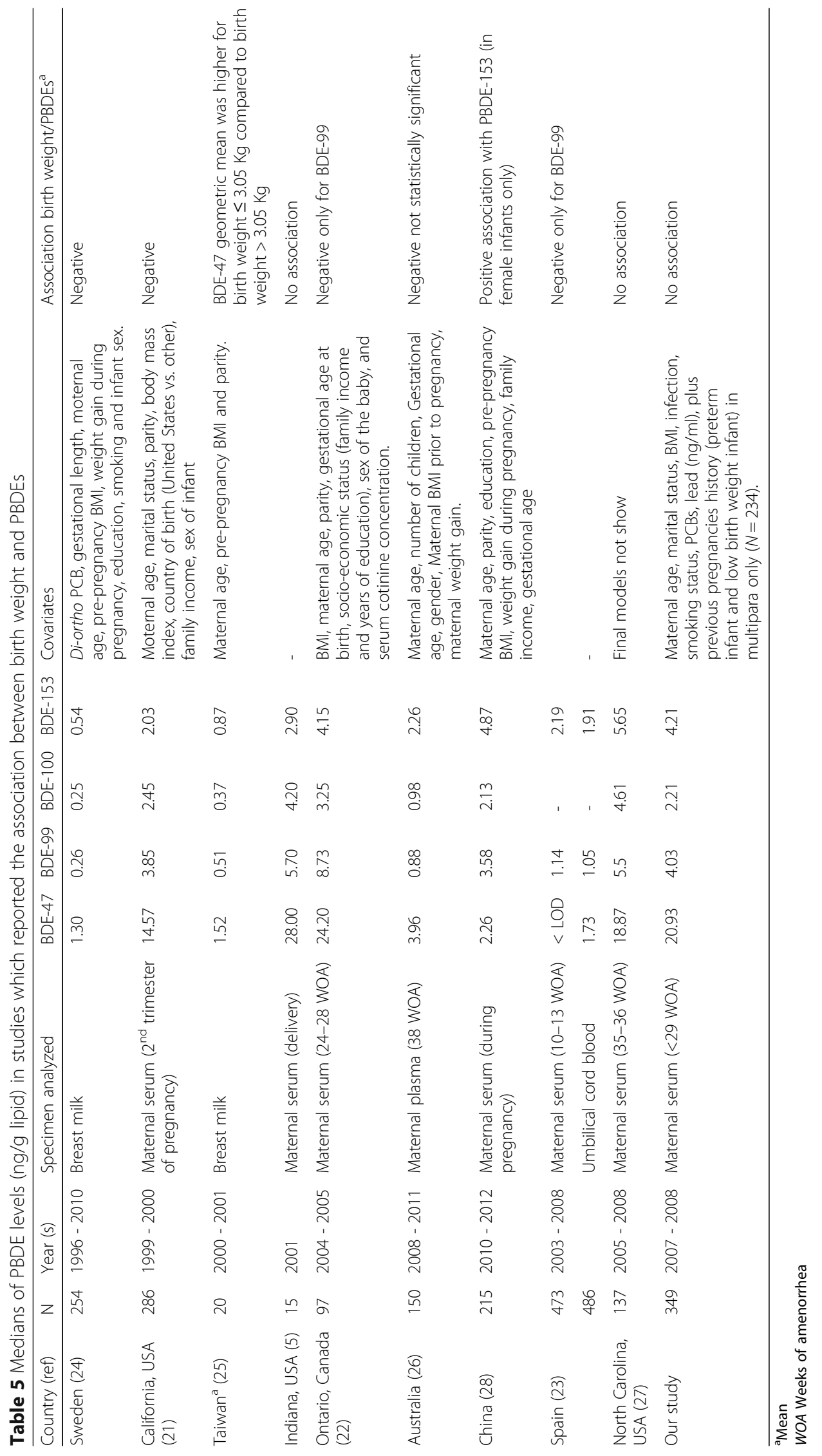


economic status (median family income was CAD\$60,000). Because BW is strongly linked to lifestyle (nutritional status, social stress and maternal health), this difference between these two populations could explain the mismatch of our results, either through a synergistic relation between socioeconomic status and PBDEs, or through residual confounding. This emphasizes the importance of choosing a pertinent set of adjustment variables to assess the relationship between BW and PBDEs.

The Ontario study [14] reported a statistically significant negative correlation between BDE-99 and BW in a group of 97 women. Their study group was also mainly Caucasian (87\%), but older compared to ours (33 versus 29 years), and much more educated (84.5\% reported obtaining a university degree or greater versus $33 \%$ in our data) and fewer were cigarette smokers (7\% versus $19 \%$ in our population). The median levels of three PBDEs $(-47,-100$, and -153$)$ in the Ontario study were similar to those in our population. However, the median level of congener BDE-99, for which they report a negative correlation with BW, is two-fold higher than in our study group. Although this may be due to inter-laboratory differences in analyses, but we cannot exclude that the Ontario study has a different exposure profile. Another limitation of the Ontario study is the small size of the study group and thus a limited statistical power to reliably affirm the decrease of 2 grams of BW per one ng/g lipids of BDE-99.

Lignell et al. [16] also found a significant negative relation between BW and the sum of PBDEs levels (BDE-47, BDE-99, BDE-100, BDE-153) measured in breast milk from 254 mothers in Sweden. These women were relatively close to our study group in terms of maternal age and education. They report that the association between PBDEs and BW was significant only after adjustment for di-ortho-PCBs (the same we considered in our analyses). However, it is important to note that the design of their study including retrospective exposure assessment (PBDEs in breast milk 3 weeks after delivery) as well as very low levels of PBDEs and narrow range of exposures (for example, the maximum level of BDE-153 in breast milk in our population was $180 \mathrm{ng} / \mathrm{g}$ lipids [16] versus $4.7 \mathrm{ng} / \mathrm{g}$ lipids in Lignell et al.' study) are significant limitations for the comparison with our study.

In the Spanish study [15], which was one of the largest among available studies, only one PBDE congener (BDE99) was significantly and negatively correlated with BW. The study group of the Spanish study was very different from our study group in terms of smoking rate $(32 \%$ versus $19 \%$ ), education level (24\% with primary educational level versus $3 \%$ in our study), and PBDE exposure (high proportion of values below LOD). Although they reported that their database contains a large number of variables which are potential confounders, we could not identify to which confounders they adjusted their final models. In addition, it is not clear at which moment of pregnancy blood was taken for PBDE levels. This missing information limits the comparison with our study.

Interestingly, we recently reported a negative correlation between PBDE levels in early pregnancy and thyroxin levels in cord blood within the same population [6]. However, BW was not correlated with thyroid hormones measured in early pregnancy or in cord blood (data not shown) and the inclusion of thyroid hormones in our models did not change any statistical relationship between PBDEs and BW (data not shown). Thus, the lack of association between PBDEs and BW should not be construed as suggesting that PBDEs are safe during fetal development. Indeed, several human and experimental studies suggest a causal link between prenatal exposure to PBDEs and attention deficit [45]. Even if several contaminants, including endocrine disrupting chemicals, have been reported to be correlated with BW [13, 14, 16, 25-30], BW is a weakly sensitive or reliable proxy for developmental toxicity of environmental pollutants in humans [43], as shown in our low risk population. Conversely, PBDEs may affect brain development without any association with BW by disrupting thyroid hormones during the fetal period.

\section{Conclusions}

Our prospectively collected data indicates that the link between PBDEs and BW does not exist, is very weak, or depends on the presence of other risk factors. However, this does not exclude the possibility of developmental PBDE toxicity via endocrine disruption.

\section{Additional file}

Additional file 1: Table S1. Description of adjustment variables. Table S2. Simple linear regression between birth weight and potential confounding factors. Table S3. Linear relations between birth weight corrected for gestational age and mothers' plasma levels of PBDEs (non-transformed) in early pregnancy $(N=349)$. Figure S1. Relation between predicted BW (obtained with proc LOESS) and gestational age at birth. (DOCX $84 \mathrm{~kb})$

\section{Abbreviations}

BMI: Body Mass Index; BW: birth weight; CAD\$: Canadian dollar; CHUS: Centre Hospitalier Universitaire de Sherbrooke; GESTE: Grossesse et Enfant en Santé-Etude sur la Thyroïde et I'Environnement; IGF: insulin-like growth factor; IGF-1: insulin-like growth factor 1; IHE: Institute of Health Economics Alberta, Canada; IUGR: intrauterine growth restriction; LOD: limit of detection; PBDE(s): polybrominated diphenyls ethers (s); PCBs: polychlorinated biphenyls; WOA: weeks of amenorrhea.

\section{Competing interests}

The authors declare that they have no competing interests.

\section{Authors' contributions}

LT is the Principal Investigator of the project. AAC has been involved in statistical modeling. JCP participated in the organization of the recruitment of pregnant women and in database construction. NA has been responsible 
for recruitment, biobank and database management, PBDE analyses, and all standard operating procedures. YKSG is a PhD student who performed statistical analyses, interpretation of data, and wrote the first draft of the manuscript. All authors read and approved the final manuscript.

\section{Acknowledgments}

This study was financed by grant 12397 from the Fonds de Recherche du Québec-Santé (FRQS), grant MOP-84551 from the Canadian Institutes of Health Research (CIHR), and NIH R21ES024841 grant. Drs. AA Cohen, J. C. Pasquier, and L. Takser are members of the Research Center of the CHUS (Centre Hospitalier Universitaire de Sherbrooke), which is supported by the FRQS. AAC is also member of the FRQS supported Centre de recherche sur le vieillissement.

Dr. N. Abdelouahab was supported by a Banting Postdoctoral Fellowship. Dr. L. Takser and Dr. AA Cohen were supported by CIHR New Investigator Awards.

YK Serme-Gbedo is supported by the Université de Sherbrooke Centre of Excellence for Mother and Child Research and CIHR - Quebec Training Network in Perinatal Research (QTNPR) Awards.

We thank the personnel of the Centre hospitalier universitaire de Sherbrooke (CHUS) maternity and the members of the CHUS Department of Family Medicine, especially Dr. Donna Cherniak, for the organization of the recruitment of pregnant women.

We are also grateful to Prof. Darel J. Hunting for the final revision of the manuscript.

\section{Author details}

'Department of Pediatrics, Faculty of Medicine, University of Sherbrooke, 3001 12e Avenue Nord, Sherbrooke, Quebec J1H 5N4, Canada. ²Department of Gynecology and Obstetrics, Faculty of Medicine, University of Sherbrooke, 3001, 12e Avenue Nord, Sherbrooke, Quebec J1H 5N4, Canada. ${ }^{3}$ Department of Family Medicine, PRIMUS Research Group, University of Sherbrooke, 3001, 12e Avenue Nord, Sherbrooke, Québec J1H 5N4, Canada.

\section{Received: 31 August 2015 Accepted: 3 April 2016}

\section{Published online: 12 April 2016}

\section{References}

1. Alaee M, Arias P, Sjödin A, Bergman A. An overview of commercially used brominated flame retardants, their applications, their use patterns in different countries/regions and possible modes of release. Environ Int. 2003:29:6.

2. Frederiksen M, Vorkamp $K$, Thomsen M, Knudsen LE. Human internal and external exposure to PBDEs-a review of levels and sources. Int J Hyg Environ Health. 2009;212:2

3. Law RJ, Covaci A, Harrad S, Herzke D, Abdallah MA-E, Fernie K, et al. Levels and trends of PBDEs and HBCDs in the global environment: status at the end of 2012. Environ Int. 2014;65.

4. Darnerud PO. Brominated flame retardants as possible endocrine disrupters. Int J Androl. 2008:31:2

5. Suvorov A, Bissonnette C, Takser L, Langlois M-F. Does 2,2',4,4'tetrabromodiphenyl ether interact directly with thyroid receptor? J Appl Toxicol JAT. 2011;31:2.

6. Abdelouahab N, Langlois M-F, Lavoie L, Corbin F, Pasquier J-C, Takser L. Maternal and cord-blood thyroid hormone levels and exposure to polybrominated diphenyl ethers and polychlorinated biphenyls during early pregnancy. Am J Epidemiol. 2013;178:5

7. Sferruzzi-Perri AN, Vaughan OR, Forhead AJ, Fowden AL. Hormonal and nutritional drivers of intrauterine growth. Curr Opin Clin Nutr Metab Care. 2013;16:3.

8. Ceccatelli R, Faass O, Schlumpf M, Lichtensteiger W. Gene expression and estrogen sensitivity in rat uterus after developmental exposure to the polybrominated diphenylether PBDE 99 and PCB. Toxicology. 2006;220:2.

9. Suvorov A, Battista M-C, Takser L. Perinatal exposure to low-dose 2,2',4,4'tetrabromodiphenyl ether affects growth in rat offspring: what is the role of IGF-1? Toxicology. 2009;260:1.

10. Shy C-G, Huang H-L, Chao H-R, Chang-Chien G-P. Cord blood levels of thyroid hormones and IGF-1 weakly correlate with breast milk levels of PBDEs in Taiwan. Int J Hyg Environ Health. 2012;215:3.

11. Xu X, Yekeen TA, Xiao Q, Wang Y, Lu F, Huo X. Placental IGF-1 and IGFBP-3 expression correlate with umbilical cord blood PAH and PBDE levels from prenatal exposure to electronic waste. Environ Pollut Barking Essex. 1987:2013:182.

12. Chiesa C, Osborn JF, Haass C, Natale F, Spinelli M, Scapillati E, et al. Ghrelin, leptin, IGF-1, IGFBP-3, and insulin concentrations at birth: is there a relationship with fetal growth and neonatal anthropometry? Clin Chem. 2008:54:3

13. Harley KG, Chevrier J, Aguilar Schall R, Sjödin A, Bradman A, Eskenazi B. Association of prenatal exposure to polybrominated diphenyl ethers and infant birth weight. Am J Epidemiol. 2011;174:8.

14. Foster WG, Gregorovich S, Morrison KM, Atkinson SA, Kubwabo C, Stewart B, et al. Human maternal and umbilical cord blood concentrations of polybrominated diphenyl ethers. Chemosphere. 2011;84:10.

15. Lopez-Espinosa M-J, Costa O, Vizcaino E, Murcia M, Fernandez-Somoano A, Iñiguez C, et al. Prenatal Exposure to Polybrominated Flame Retardants and Fetal Growth in the INMA Cohort (Spain). Environ Sci Technol. 2015:49:16.

16. Lignell S, Aune M, Darnerud PO, Hanberg A, Larsson SC, Glynn A. Prenatal exposure to polychlorinated biphenyls (PCBs) and polybrominated diphenyl ethers (PBDEs) may influence birth weight among infants in a Swedish cohort with background exposure: a cross-sectional study. Environ Health Glob Access Sci Source. 2013;12.

17. Chao H-R, Wang S-L, Lee W-J, Wang Y-F, Päpke O. Levels of polybrominated diphenyl ethers (PBDEs) in breast milk from central Taiwan and their relation to infant birth outcome and maternal menstruation effects. Environ Int. 2007;33:2.

18. Stasinska A, Heyworth J, Reid A, Callan A, Odland JØ, Trong Duong P, et al. Polybrominated diphenyl ether (PBDE) concentrations in plasma of pregnant women from Western Australia. Sci Total Environ. 2014;493.

19. Mazdai A, Dodder NG, Abernathy MP, Hites RA, Bigsby RM. Polybrominated diphenyl ethers in maternal and fetal blood samples. Environ Health Perspect. 2003:111:9.

20. Miranda ML, Anthopolos R, Wolkin A, Stapleton HM. Associations of birth outcomes with maternal polybrominated diphenyl ethers and thyroid hormones during pregnancy. Environ Int. 2015;85.

21. Chen L, Wang C, Cui C, Ding G, Zhou Y, Jin J, et al. Prenatal exposure to polybrominated diphenyl ethers and birth outcomes. Environ Pollut Barking Essex. 1987;2015:206.

22. Choi G, Kim S, Kim S, Kim S, Choi Y, Kim H-J, et al. Occurrences of major polybrominated diphenyl ethers (PBDEs) in maternal and fetal cord blood sera in Korea. Sci Total Environ. 2014;491.

23. Forde MS, Dewailly E, Robertson L, Laouan Sidi EA, Côté S, Dumas $P$, et al. Prenatal exposure to persistent organic pollutants and polybrominated diphenyl ethers in 10 Caribbean countries. Environ Res. 2014;133.

24. Vuong AM, Webster GM, Romano ME, Braun JM, Zoeller RT, Hoofnagle AN, et al. Maternal Polybrominated Diphenyl Ether (PBDE) Exposure and Thyroid Hormones in Maternal and Cord Sera: The HOME Study, Cincinnati, USA. Environ Health Perspect. 2015;123:10.

25. Al-Saleh I, Shinwari N, Mashhour A, Rabah A. Birth outcome measures and maternal exposure to heavy metals (lead, cadmium and mercury) in Saud Arabian population. Int J Hyg Environ Health. 2014;217:2.

26. García-Esquinas E, Pérez-Gómez B, Fernández-Navarro P, Fernández MA, de Paz C, Pérez-Meixeira AM, et al. Lead, mercury and cadmium in umbilical cord blood and its association with parental epidemiological variables and birth factors. BMC Public Health. 2013.

27. Wood RJ. Manganese and birth outcome. Nutr Rev. 2009;67:7

28. Kippler M, Tofail F, Gardner R, Rahman A, Hamadani JD, Bottai M, et al. Maternal cadmium exposure during pregnancy and size at birth: a prospective cohort study. Environ Health Perspect. 2012;120:2.

29. Al-Saleh I, Al-Rouqi R, Obsum CA, Shinwari N, Mashhour A, Billedo G, et al. Mercury $(\mathrm{Hg})$ and oxidative stress status in healthy mothers and its effect on birth anthropometric measures. Int J Hyg Environ Health. 2014;217:4.

30. King E, Shih G, Ratnapradipa D, Quilliam DN, Morton J, Magee SR. Mercury, lead, and cadmium in umbilical cord blood. J Environ Health. 2013:75:6.

31. Covaci A, Voorspoels S. Optimization of the determination of polybrominated diphenyl ethers in human serum using solid-phase extraction and gas chromatography-electron capture negative ionization mass spectrometry. J Chromatogr B Analyt Technol Biomed Life Sci. 2005:827:2.

32. SAS Institute Inc. 2012. What's New in SAS ${ }^{\circledR}$ 9.3. Cary, NC: SAS Institute Inc. [Internet]. http://support.sas.com/documentation/cdl/en/whatsnew/64209/ PDF/default/whatsnew.pdf. Accessed 07 Apr 2016.

33. Peltier MR, Koo H-C, Getahun D, Menon R. Does exposure to flame retardants increase the risk for preterm birth? J Reprod Immunol. 2015;107. 
34. Wilcox AJ, Weinberg CR, Basso O. On the pitfalls of adjusting for gestational age at birth. Am J Epidemiol. 2011;174:9.

35. Norén K, Weistrand C, Karpe F. Distribution of PCB congeners, DDE, hexachlorobenzene, and methylsulfonyl metabolites of PCB and DDE among various fractions of human blood plasma. Arch Environ Contam Toxicol. 1999;37:3.

36. Mohammed A, Eklund A, Ostlund-Lindqvist AM, Slanina P. Distribution of toxaphene, DDT, and PCB among lipoprotein fractions in rat and human plasma. Arch Toxicol. 1990;64:7.

37. Darmady JM, Postle AD. Lipid metabolism in pregnancy. Br J Obstet Gynaecol. 1982;89:3.

38. Institute of Health Economics. Alberta Canada. Determinants and Prevention of Low Birth Weight: A Synopsis of the Evidence December 2008 [Internet]. http://www.google.fr/url?sa=t\&rct=j\&q=\&esrc=s\&source=web\&cd=1\&ved= oCCkQFjAA\&url=http\%3A\%2F\%2Fwww.ihe.ca\%2Findex.php\%3F\%2F download\%2Fdeterminants_and_prevention_of_low_birth_weight_a_ synopsis_of_the_evidence.pdf\&ei=VRIVVcaYJYepgwSF_YCgCA\&usg= AFQjCNE5bYyVyiJb9RSDYfQnkfzPjvOLaQ\&bvm=bv.94911696,d.eXY. Assessed 3 Jun 2015.

39. Lockitch G. Maternal-fetal risk assessment. Clin Biochem. 2004;37:6.

40. Government of Canada HC. Second Report on Human Biomonitoring of Environmental Chemicals in Canada [Health Canada, 2013] [Internet]. http://www.hc-sc.gc.ca/ewh-semt/pubs/contaminants/chms-ecms-cycle2/ index-eng.php. Assessed 6 May 2015 May.

41. Government of Canada SDC. Family Life - Age of Mother at Childbirth/ Indicators of Well-being in Canada [Internet]. http://well-being.esdc.gc.ca/ misme-iowb/.3ndic.1t.4r@-eng.jsp?iid=75. Assessed 26 Nov 2015.

42. Government of Canada SC. Median total income, by family type, by province and territory (All census families) [lnternet]. http://www.statcan.gc ca/tables-tableaux/sum-som/101/cst01/famil108a-eng.htm. Assessed 07 Apr 2016

43. Wilcox AJ. On the importance-and the unimportance-of birthweight. Int $J$ Epidemiol. 2001;30:6

44. Rothman KJ, Greenland S. Causation and causal inference in epidemiology Am J Public Health. 2005;95 Suppl 1:S144-50.

45. Berghuis SA, Bos AF, Sauer PJJ, Roze E. Developmental neurotoxicity of persistent organic pollutants: an update on childhood outcome. Arch Toxicol. 2015;89:5

\section{Submit your next manuscript to BioMed Central and we will help you at every step:}

- We accept pre-submission inquiries

- Our selector tool helps you to find the most relevant journal

- We provide round the clock customer support

- Convenient online submission

- Thorough peer review

- Inclusion in PubMed and all major indexing services

- Maximum visibility for your research

Submit your manuscript at www.biomedcentral.com/submit 